\title{
Dual-channel functional electrical stimulation improvements in speed-based gait classifications
}

This article was published in the following Dove Press journal:

Clinical Interventions in Aging

27 February 2013

Number of times this article has been viewed

\author{
Shmuel Springer ${ }^{1,2}$ \\ Yocheved Laufer' \\ Meni Becher ${ }^{1,2}$ \\ Jean-Jacques Vatine ${ }^{3,4}$ \\ 'Department of Physical Therapy, \\ Faculty of Social Welfare and \\ Health Sciences, University of \\ Haifa, Haifa, ${ }^{2}$ Clinical Department, \\ Bioness Neuromodulation, Ra'anana, \\ ${ }^{3}$ Outpatient and Research Division, \\ Reuth Medical Center, Tel Aviv, \\ ${ }^{4}$ Department of Rehabilitation \\ Medicine, Sackler Faculty of Medicine, \\ Tel-Aviv University, Tel-Aviv, Israel
}

Correspondence: Yocheved Laufer Faculty of Social Welfare and Health Studies, Eshkol Building, Room 910, University of Haifa, Haifa, Israel 31905 Tel +972547654619

Fax +97248288140

Email yocheved@research.haifa.ac.il
Background: Functional electrical stimulation (FES) is becoming an accepted treatment method for enhancing gait performance in patients who present with gait difficulties resulting from hemiparesis. The purpose of this study was to test whether individuals with hemiparesis who have varied gait speeds, which place them in different functional categories, benefit to the same extent from the application of FES.

Methods: Thirty-six subjects with chronic hemiparesis demonstrating foot-drop and deficits in knee and/or hip control were fitted with a dual-channel FES system activating the dorsiflexors and hamstring muscles. Gait was assessed during a 2-minute walk test with and without stimulation. A second assessment was conducted after 6 weeks of daily use. Analysis was performed with the subjects stratified into three functional ambulation classes according to their initial gait categories.

Results: The dual-channel FES improved the gait velocity of all three subgroups. No minimal gait velocity was required in order to gain benefits from FES. For example, subjects with limited household ambulation capabilities improved their gait speed by $63.3 \%$ (from $0.30 \pm 0.09 \mathrm{~m} / \mathrm{sec}$ to $0.49 \pm 0.20 \mathrm{~m} / \mathrm{sec} ; P<0.01$ ), while subjects with functional community ambulation capabilities improved their gait speed by $25.5 \%$ (from $0.90 \pm 0.11 \mathrm{~m} / \mathrm{sec}$ to $1.13 \pm 0.22 \mathrm{~m} / \mathrm{sec}$; $P<0.01)$.

Conclusion: Dual-channel FES positively affects gait velocity in patients with chronic hemiparesis, regardless of their initial gait velocity. Furthermore, gait velocity gains may be large enough to change an individual's ambulation status to a higher functional category.

Keywords: hemiparesis, functional electrical stimulation, gait velocity, ambulation

\section{Introduction}

Restoration of independent and functional ambulation is a major rehabilitation goal for patients with hemiparesis. Although the majority of these patients achieve some degree of independent gait, many do not reach a walking level that enables them to perform activities of daily living. ${ }^{1,2}$ The inability to resume community level ambulation is estimated to afflict at least $50 \%$ of individuals with hemiparesis, resulting in diminished independence and quality of life. ${ }^{1,3}$ Furthermore, gait performance following termination of conventional therapy is characterized by elevated energy cost, poor endurance, and repeated falls with ensuing dire consequences. ${ }^{4}$

Gait speed is related to lower extremity strength and motor control, ${ }^{5}$ balance and functional mobility, ${ }^{6}$ gait endurance, ${ }^{7}$ energy expenditure and disability. ${ }^{8}$ Gait speed is considered to be a significant, sensitive, and reliable marker of hemiparetic gait recovery. ${ }^{9}$ Improved gait velocity is associated with better function and quality 
of life. ${ }^{10}$ The degree to which walking speed is impaired following a stroke can vary widely and relates to the severity of the patient's lower extremity motor impairment. ${ }^{11}$ Gait speed can be used to classify individuals post stroke into different functional walking categories. Perry et al ${ }^{12}$ suggested a three-category classification of gait ability: limited household ambulation-gait velocity $<0.4 \mathrm{~m} / \mathrm{sec}$; limited community ambulation-gait velocity of $0.4-0.8 \mathrm{~m} / \mathrm{sec}$; and functional community ambulation-gait velocity $>0.8 \mathrm{~m} / \mathrm{sec}$. Transitioning to a higher ambulation category is associated with substantially better function and quality of life, especially with regard to mobility and community participation. ${ }^{10}$

Functional electrical stimulation (FES) has been used for many years to assist patients who present with gait difficulties resulting from hemiparesis. Because of technological advances and commercially available systems, the use of FES as an orthotic device is becoming an accepted intervention for enhancing gait performance, resulting in increased physical functioning and community participation. ${ }^{13}$ Furthermore, prolonged use of FES as an orthotic device, even by patients with chronic hemiparesis, has been shown to have a therapeutic effect, with some of the gains in gait performance maintained even when FES is not activated. ${ }^{13-15}$

Traditionally, peroneal stimulation to ameliorate footdrop, which entails the use of two electrodes located over the common peroneal nerve and tibialis anterior muscle, is the most commonly used form of FES. ${ }^{16}$ However, FES of the dorsiflexors does not improve all gait deficits associated with hemiparetic gait, because many patients with hemiparesis also demonstrate other muscle control deficits, such as insufficient knee and hip control. In recent years, multichannel FES has been used to include additional muscle groups by placing more than one pair of electrodes near motor points or nerves targeted for activation. Thus, stimulation of different combinations of muscle groups has been shown to improve the gait speed of patients with hemiparesis. ${ }^{17,18}$ However, to the best of our knowledge, none of the previous studies examined whether the improvement in speed is dependent on the initial gait speed deficits of the users. In particular, they did not explore whether individuals with varied gait speeds, which place them in different functional categories, benefit to the same extent from application of FES.

In recent research, it was demonstrated that specific use of multichannel stimulation, ie, dual-channel stimulation applied to the ankle dorsiflexors during the swing phase and to the hamstrings during the stance phase, improved the temporal as well as kinematic characteristics of gait in patients with insufficient knee and ankle control. ${ }^{19,20}$ Following these studies, the objective of the current study was to determine whether the impact of dual-channel FES applied to these muscles is dependent on the individuals' initial deficits in gait speed.

\section{Materials and methods Design and participants}

Data in this study were derived from a parent study which evaluated the effects of daily peroneal and thigh (hamstring or quadriceps) muscle FES on the temporal aspects of gait performance in individuals with hemiparesis. ${ }^{19}$ The findings of the parent study suggested that dual-channel application of FES improves the temporal characteristics of gait better than single-channel FES in this group of patients. The study was approved by the institutional review board of the Reuth Medical Center, Israel. All subjects signed an informed consent form.

The present analysis included only subjects who were at least 6 months post-diagnosis and who had the dual-channel FES applied to the peroneal and hamstring muscles (and not to the quadriceps, as in the parent study). Peroneal stimulation was intended to ameliorate foot-drop, and hamstring stimulation was applied to assist with hip and knee control (ie, to reduce knee hyperextension and/or improve hip extension).

Thirty-six subjects with chronic hemiparesis were included in the analysis. Subjects were recruited from outpatient clinics at rehabilitation centers in the central region of Israel. Inclusion criteria were: diagnosis of an upper motor neuron lesion; hamstring strength less than $4 / 5$, as determined by manual muscle testing; foot-drop, ie, toe drag during walking; lower limb spasticity ranked at 0-3 according to the modified Ashworth scale; ability to walk independently or with an assistance device (eg, a cane or walker) or spot guarding for at least $10 \mathrm{~m}$; ability to follow multiple-step directions, with a score greater than 21 on the Mini Mental State Examination; ${ }^{21}$ and sufficient response to electrical stimulation, ie, visible muscle contractions of each designated muscle, as tested in a seated position. Exclusion criteria were a cardiac pacemaker, a skin lesion at the site of the stimulation electrodes, severe neglect (Star cancellation test $<30$ ), or major depression.

\section{Dual-channel FES system}

The dual-channel FES system used in this study (NESS L300Plus Bioness, Valencia, CA, USA) consisted of lower leg and thigh cuffs, a gait sensor, and a control unit that 
communicates by radiofrequency signals (Figure 1). The lower leg and thigh cuffs were designed to enable accurate and repeatable placement. Each cuff integrates two electrodes and a stimulation unit. The electrodes of the lower leg cuff were located over the common peroneal nerve and the tibialis anterior muscle. The electrodes of the thigh cuff were positioned over the hamstring muscles. The gait sensor detects the force under the foot using a force-sensitive resistor. It uses a dynamic gait tracking algorithm to detect whether the foot is on the ground or in the air and transmits radio signals to synchronize stimulation according to the timing of gait events. A miniature control unit enables the user to activate the system and receive information regarding its status. A hand-held computer is used by a clinician during the fitting process to set the stimulation parameters (eg, intensity, pulse frequency) and timing of the stimulation.

The peroneal stimulation (symmetrical biphasic, phase duration $200 \mu \mathrm{sec}$, pulse rate $30 \mathrm{~Hz}$ ) was configured to the swing phase so as to ameliorate foot-drop, while the hamstring stimulation (symmetrical biphasic, phase duration $300 \mu \mathrm{sec}$, pulse rate $40 \mathrm{~Hz}$ ) was delivered from mid stance to initial swing in order to assist with knee and hip control.

\section{Gait velocity evaluation}

Gait velocity was assessed at baseline and after 6 weeks of conditioning by a qualified physical therapist as follows: immediately after fitting the dual-channel FES system and adjusting the electrode placement and stimulation parameters, each patient underwent gait evaluations with and without FES. This initial assessment (T1) was followed by a 6-week adaptation period during which participants increased their daily use of the system according to a fixed protocol, so that by the end of the fourth week, all subjects were able to use

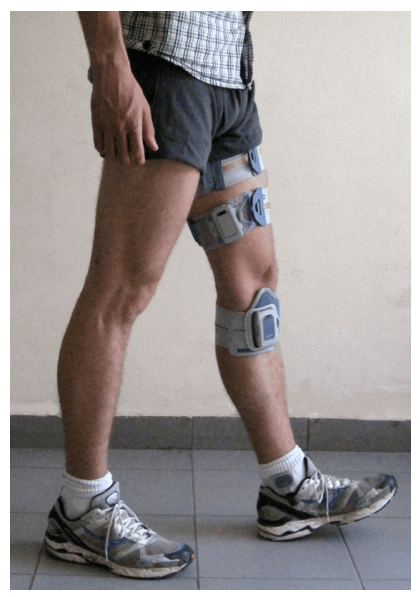

Figure I The Ness L300Plus system. the system for the entire day. A second assessment (T2) was conducted after this 6 -week period. Under each walking condition (ie, with and without FES) in both assessments, gait velocity was measured during a 2-minute walk test. Under each 2-minute walk test condition, the subjects were instructed to walk as far as they could, at their self-selected normal walking speed, back and forth along a $50 \mathrm{~m}$ hallway, turning around each time they reached the end of the walkway. Average gait speed was determined by dividing the distance covered in 2 minutes by 120 seconds.

The 2-minute walk test has been shown to correlate well with the longer 6-minute and 12-minute walk tests, ${ }^{22}$ and was selected to minimize fatigue effects. This commonly used gait performance test is highly reliable and frequently used to evaluate gait performance in individuals with hemiparesis after stroke. ${ }^{23}$

\section{Statistical analysis}

Descriptive statistics (mean \pm standard deviation) were used to differentiate between three subgroups according to their initial gait velocity, as determined at $\mathrm{T} 1$ without stimulation: subgroup A (limited household ambulation); subgroup B (limited community ambulation); and subgroup C (functional community ambulation). A $3 \times 2 \times 2$ (group $\times$ condition $\times$ time) repeated-measures analyses of variance was performed in order to examine the effect of FES versus no stimulation and time on gait velocity in each subgroup. A separate $2 \times 2$ (condition $\times$ time) analysis of variance was also performed in order to examine the effect of FES and time on the entire group. Analyses of variances were followed by preplanned comparisons based on adjusted Tukey-Kramer tests. Significance was determined at $P<0.05$. The analysis was conducted using SAS version 9.1 (SAS Institute, Cary, $\mathrm{NC}, \mathrm{USA}$ ).

\section{Results}

Data on subject characteristics are summarized in Table 1. Of the 36 subjects, 15 subjects were classified as subgroup A (limited household ambulation), 15 subjects as subgroup B (limited community ambulation), and only six as subgroup $\mathrm{C}$ (functional community ambulation). Table 2 presents all gait velocity results with and without FES at T1 and T2 by subgroup as well as for all subjects combined. Gait velocity results for all three subgroups $(\mathrm{A}-\mathrm{C})$ are also presented in Graph 1.

The two-way analysis of variance examining the effect of stimulation condition and time on the entire group $(2 \times 2$ analysis $)$ indicated significant effects for condition $(P<0.0001)$ and time $(P<0.0001)$, as well as a significant 


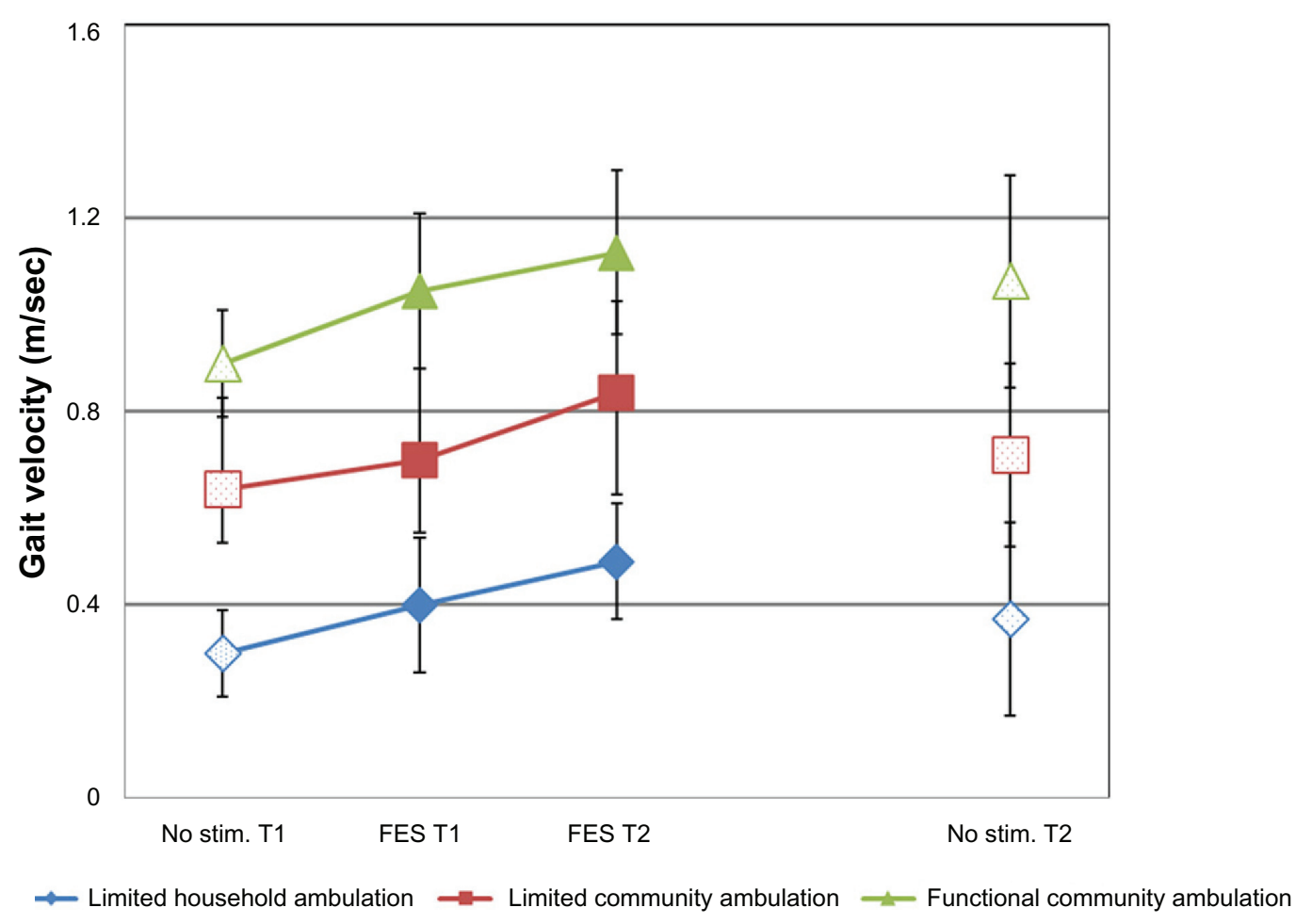

Graph I Effect of functional electrical stimulation on gait velocity in the three subgroups of ambulation categories.

interaction effect for condition $\times$ time $(P=0.02)$. The three-way analysis of variance examining the effect of FES and time on each subgroup separately $(3 \times 2 \times 2$ analysis $)$ indicated significant effects for group, time, and condition $(P<0.0001)$. An interaction effect was also found for group $\times$ condition $\times$ time $(P=0.04)$. Preplanned comparisons based on adjusted Tukey-Kramer tests were used to investigate the four fundamental effects of FES as delineated (also shown in Table 3).

\section{Orthotic effect}

The orthotic effect refers to the change in gait speed during ambulation while using the FES device, as compared with ambulation without stimulation. Two comparisons were made

Table I Subject characteristics

\begin{tabular}{lllcl}
\hline Group & $\begin{array}{l}\text { Age } \\
\text { means } \pm \text { SD } \\
\text { (years) }\end{array}$ & $\begin{array}{l}\text { Gender } \\
(\text { F/M) }\end{array}$ & $\begin{array}{l}\text { Years post } \\
\text { diagnosis } \\
\text { means } \pm \text { SD }\end{array}$ & $\begin{array}{l}\text { Paretic side } \\
\text { (right/left) }\end{array}$ \\
\hline A $(n=15)$ & $60.53 \pm 14.66$ & $5 / 10$ & $4.53 \pm 4.26$ & $5 / 10$ \\
$B(n=15)$ & $55.07 \pm 15.49$ & $6 / 9$ & $5.48 \pm 3.45$ & $11 / 4$ \\
C $(n=6)$ & $54.67 \pm 18.54$ & $4 / 2$ & $12.67 \pm 8.71$ & $3 / 3$ \\
Entire group & $57.28 \pm 15.46$ & $15 / 21$ & $6.29 \pm 5.61$ & $19 / 17$ \\
$(n=36)$ & & & & \\
\hline
\end{tabular}

Notes: Group A, limited household ambulation; group B, limited community ambulation; group $\mathrm{C}$, functional community ambulation. in order to reflect the orthotic effect over the trial period: orthotic effect at T1 (ie, FES at T1 versus no stimulation at T1) and orthotic effect at T2 (ie, FES at T2 versus no stimulation at T2). The orthotic effect at T1 was found to be significant in all three subgroups, as well as in the entire group analysis. For example, in subgroup A, gait speed with FES increased by $33.3 \%$ from $0.30 \pm 0.09 \mathrm{~m} / \mathrm{sec}$ to $0.40 \pm 0.14 \mathrm{~m} / \mathrm{sec}(P<0.01)$. In the entire group, gait speed increased at $\mathrm{T} 1$ by $18.5 \%$ from $0.54 \pm 0.24 \mathrm{~m} / \mathrm{sec}$ to $0.63 \pm 0.27 \mathrm{~m} / \mathrm{sec}(P<0.001)$.

After 6 weeks of using the FES system (T2), the orthotic effect was found to be significant in the entire group $(P<0.001)$, as well as in subgroups $\mathrm{A}$ and $\mathrm{B}(P=0.0003$ and $P<0.0001$, respectively), but not in subgroup $\mathrm{C}$ among the functional community ambulators.

Table 2 Group means and standard deviations of gait velocity under both conditions at study initiation (TI) and after 6 weeks (T2)

\begin{tabular}{llllll}
\hline Group & TI & & T2 & \\
\cline { 2 - 3 } \cline { 5 - 6 } & $\begin{array}{l}\text { No } \\
\text { stimulation }\end{array}$ & FES & & $\begin{array}{l}\text { No } \\
\text { stimulation }\end{array}$ & FES \\
\hline$A(n=15)$ & $0.30 \pm 0.09$ & $0.40 \pm 0.14$ & $0.37 \pm 0.12$ & $0.49 \pm 0.20$ \\
$B(n=15)$ & $0.64 \pm 0.11$ & $0.70 \pm 0.15$ & $0.7 I \pm 0.21$ & $0.84 \pm 0.19$ \\
$C(n=6)$ & $0.90 \pm 0.11$ & $1.05 \pm 0.16$ & & $1.07 \pm 0.17$ & $1.13 \pm 0.22$ \\
Entire group & $0.54 \pm 0.24$ & $0.63 \pm 0.27$ & & $0.61 \pm 0.30$ & $0.74 \pm 0.3 I$ \\
$(n=36)$ & & & &
\end{tabular}

Abbreviation: FES, functional electrical stimulation. 
Table 3 Summary of Tukey-Kramer preplanned comparisons

\begin{tabular}{llllll}
\hline Group & $\begin{array}{l}\text { Orthotic } \\
\text { effect TI }\end{array}$ & $\begin{array}{l}\text { Orthotic } \\
\text { effect T2 }\end{array}$ & $\begin{array}{l}\text { Therapeutic } \\
\text { effect }\end{array}$ & $\begin{array}{l}\text { Habituation } \\
\text { effect }\end{array}$ & $\begin{array}{l}\text { Over all } \\
\text { FES effect }\end{array}$ \\
\hline A & 0.0006 & 0.0003 & NS $(0.4584)$ & 0.0219 & 0.0003 \\
B & 0.0354 & $<0.0001$ & NS $(0.4257)$ & 0.0002 & 0.0001 \\
C & 0.0007 & NS $(0.1087)$ & NS $(0.4704)$ & NS $(0.6263)$ & 0.0096 \\
Entire group & $<0.001$ & $<0.001$ & 0.001 & $<0.001$ & $<0.001$ \\
\hline
\end{tabular}

Notes: Orthotic effect: TI-TI, no stimulation versus TI FES; orthotic effect T2-T2, no stimulation versus T2 FES. Therapeutic effect T2 no stimulation versus TI no stimulation. Habituation effect T2 FES versus TI FES. Over all FES effect TI no stimulation versus T2 FES.

Abbreviation: FES, functional electrical stimulation; NS, not statiscally significant.

\section{Therapeutic effect}

The therapeutic effect, which refers to the carryover impact of FES, was measured by comparing the gait speed without stimulation at $\mathrm{T} 1$ with the gait speed in the same condition at T2. Although higher gait speeds were measured at T2 in all three subgroups, none of the changes reached significance. However, the entire group analysis did demonstrate a significant therapeutic effect $(P=0.001)$.

\section{Habituation effect}

The habituation effect illustrates the conditioning of the user to the FES device. It compares the baseline gait speed with FES at T1 with walking using the system after a 6-week adaptation period at $\mathrm{T} 2$. The habituation effect was found to be significant in the entire group $(P<0.001)$, as well as in subgroups $\mathrm{A}$ and $\mathrm{B}(P=0.02$ and $P<0.0002$, respectively), but not in subgroup $C$. The adaptation period increased gait speed with FES in subgroup A, subgroup B, and the entire group by $22.5 \%, 20 \%$, and $17 \%$, respectively.

\section{Overall FES effect}

The overall FES effect summarizes the inclusive FES impact by comparing the baseline gait speed without stimulation at $\mathrm{T} 1$ with the gait speed with stimulation at $\mathrm{T} 2$. This outcome was found to be significant in all three subgroups, as well as in the entire group analysis. The subgroup with the largest improvement was that of the limited household ambulators (subgroup A), which improved by $63.3 \%$ from $0.30 \pm 0.09 \mathrm{~m} /$ sec to $0.49 \pm 0.20 \mathrm{~m} / \mathrm{sec}(P<0.01)$.

\section{Discussion}

This study investigated the effect of dual-channel FES, applied to the hamstrings and dorsiflexors muscles, on gait speed of patients with chronic hemiparesis with varied gait abilities. Our goal was to examine the effect of FES on gait velocity in patients differing in their initial ambulatory capabilities, as determined by three functional ambulation categories. The results showed that dual-channel FES had a positive effect on gait velocity in all three subgroups. In addition, no minimal gait velocity was required in order to gain benefits from FES. The household ambulators, who were characterized by very low gait speed and probably had more severe neurological deficits, enhanced their walking speed as well.

The National Institutes of Health has emphasized the need for research in order to assess the effectiveness of rehabilitation interventions for subjects post stroke. ${ }^{24}$ The present study contributes to this goal by demonstrating that FES can be a useful intervention for a wide variety of patients following stroke. Furthermore, the study was conducted in subjects with chronic hemiparesis who were, on average, 6.3 years out from diagnosis. The performance of individuals with chronic hemiparesis is generally expected to either remain steady or to deteriorate over time. ${ }^{25}$ Thus, it seems unlikely that these results would have been achieved without the use of FES.

The overall FES effect, namely the contribution of FES following the adaptation period, was found to be significant and larger than $0.1 \mathrm{~m} / \mathrm{sec}$ in all three subgroups, as well as in the entire group analysis. Previous research findings indicate that even small improvements in gait speed are sufficient to detect real clinical changes in disabled elderly individuals. ${ }^{23}$ For example, based on a data set that included 100 individuals post stroke, Perera et $\mathrm{al}^{26}$ estimated a change of $0.04-0.06 \mathrm{~m} / \mathrm{sec}$ in gait speed to be a small meaningful change. In older adults without specific impairments, as well as in adults after a hip fracture, a change in gait velocity of $0.1 \mathrm{~m} / \mathrm{sec}$ has been determined as a minimal clinically important difference. ${ }^{27}$

The magnitude of the increase in gait velocity with FES (overall FES effect) in subgroups A and B was large enough to change an individual's ambulation status from limited household ambulation to limited community ambulation and from limited community ambulation to functional community ambulation. This is of particular significance, because it has been demonstrated that gait velocity gains which result in a transition to a higher ambulation category are associated with better function and quality of life. ${ }^{10}$ 
Although all three subgroups improved their gait speed with FES, the improvement pattern was not similar. While the subjects in the two slower subgroups continued to improve their performance with FES, as demonstrated by the significant habituation effect, those in the fastest subgroup (subgroup C) showed a more immediate FES effect. One possible explanation for this difference is that patients who can walk relatively fast and are functional community ambulators may require a longer period of use (ie, $>6$ weeks) of the FES in order to demonstrate a habituation effect. ${ }^{28}$ Moreover, lack of a significant effect in the subgroup of the functional community ambulators may be related to its small size, which may also explain the lack of an orthotic effect in this subgroup at T2. Thus, the differences in improvement with FES over time between the subgroups cannot be addressed adequately with the current data. To understand these differences fully, longer longitudinal studies with a larger sample should be planned. The promising results of the present investigation suggest that such studies are warranted.

The carryover effect to gait without the application of FES was found to be significant only in the entire group analysis. Although not all previous studies of FES have demonstrated carryover effects, ${ }^{29-31}$ there is a growing body of evidence indicating that FES may have therapeutic effects which persist beyond the period of stimulation. ${ }^{28,32} \mathrm{~A}$ possible explanation for these results may be related to the relatively small size of the subgroups, such that the therapeutic effect becomes evident only in the entire group analysis. In addition, positive carryover effects may necessitate longer periods of FES and need to be investigated further.

The present study has several limitations, including the protocol duration of 6 weeks and the relatively small sample size, especially in the subgroup of functional community ambulators. The initial mean gait velocity in the present sample $(0.54 \pm 0.24 \mathrm{~m} / \mathrm{sec})$ is consistent with other studies involving subjects with chronic hemiparesis. ${ }^{33,34}$ It can thus be assumed that the gait velocity distribution in our study is also representative of the population of patients with chronic hemiparesis who have deficits in knee and ankle control, because not many patients with these limitations are expected to obtain a baseline velocity greater than $0.8 \mathrm{~m} / \mathrm{sec}$. Further investigations should be undertaken to confirm our study results in larger samples and with longer durations of use. Finally, our results demonstrated gait velocity gains with FES that are associated with better function and quality of life. However, the study did not include specific measures of function and social participation. Thus, future research using appropriate outcome measures for function and social participation in addition to gait speed are warranted.

\section{Conclusion}

The study indicates that dual-channel FES positively affects gait velocity in patients with chronic hemiparesis, regardless of their initial status in terms of gait performance. Furthermore, the gains in gait velocity are apparently of a magnitude that may have functional implications for an individual's degree of independent ambulation, enabling individuals who were initially home-bound to acquire limited community ambulation capabilities, and those who had limited community ambulation capabilities to reach the level of functional community ambulation. Because this study included a relatively small sample size, future studies should be carried out in order to confirm the current results.

\section{Disclosure}

SS and MB are employed by Bioness Neuromodulation, the manufacturer of the L300Plus. Other authors have no conflicts of interest to declare.

\section{References}

1. Bonita R, Solomon N, Broad JB. Prevalence of stroke and strokerelated disability. Estimates from the Auckland stroke studies. Stroke. 1997;28(10):1898-1902.

2. Lord SE, McPherson K, McNaughton HK, Rochester L, Weatherall M. Community ambulation after stroke: how important and obtainable is it and what measures appear predictive? Arch Phys Med Rehabil. 2004; 85(2):234-239.

3. Bowden MG, Embry AE, Gregory CM. Physical therapy adjuvants to promote optimization of walking recovery after stroke. Stroke Res Treat. 2011;2011:601416.

4. Daly JJ, Roenigk K, Holcomb J, et al. A randomized controlled trial of functional neuromuscular stimulation in chronic stroke subjects. Stroke. 2006;37(1):172-178.

5. Bohannon RW, Walsh S. Nature, reliability, and predictive value of muscle performance measures in patients with hemiparesis following stroke. Arch Phys Med Rehabil. 1992;73(8):721-725.

6. Tyson SF, DeSouza LH. Reliability and validity of functional balance tests post stroke. Clin Rehabil. 2004;18(8):916-923.

7. Fulk GD, Echternach JL, Nof L, O’Sullivan S. Clinometric properties of the six-minute walk test in individuals undergoing rehabilitation poststroke. Physiother Theory Pract. 2008;24(3):195-204.

8. Cunha IT, Lim PA, Henson H, Monga T, Qureshy H, Protas EJ. Performance-based gait tests for acute stroke patients. Am J Phys Med Rehabil. 2002;81(11):848-856.

9. Dickstein R. Rehabilitation of gait speed after stroke: a critical review of intervention approaches. Neurorehabil Neural Repair. 2008;22(6): 649-660.

10. Schmid A, Duncan PW, Studenski S, et al. Improvements in speed-based gait classifications are meaningful. Stroke. 2007;38(7):2096-2100.

11. Patterson SL, Forrester LW, Rodgers MM, et al. Determinants of walking function after stroke: differences by deficit severity. Arch Phys Med Rehabil. 2007;88(1):115-119.

12. Perry J, Garrett M, Gronley JK, Mulroy SJ. Classification of walking handicap in the stroke population. Stroke. 1995;26(6):982-989. 
13. Laufer Y, Hausdorff JM, Ring H. Effects of a foot drop neuroprosthesis on functional abilities, social participation, and gait velocity. Am JPhys Med Rehabil. 2009;88(1):14-20.

14. Taylor PN, Burridge JH, Dunkerley AL, et al. Clinical use of the Odstock dropped foot stimulator: its effect on the speed and effort of walking. Arch Phys Med Rehabil. 1999;80(12):1577-1583.

15. Thrasher TA, Popovic MR. Functional electrical stimulation of walking: function, exercise and rehabilitation. Ann Readapt Med Phys. 2008;51(6):452-460.

16. Peckham PH, Knutson JS. Functional electrical stimulation for neuromuscular applications. Annu Rev Biomed Eng. 2005;7:327-360.

17. Kim JH, Chung Y, Kim Y, Hwang S. Functional electrical stimulation applied to gluteus medius and tibialis anterior corresponding gait cycle for stroke. Gait Posture. 2012;36(1):65-67.

18. Embrey DG, Holtz SL, Alon G, Brandsma BA, McCoy SW. Functional electrical stimulation to dorsiflexors and plantar flexors during gait to improve walking in adults with chronic hemiplegia. Arch Phys Med Rehabil. 2010;91(5):687-696.

19. Springer S, Vatine JJ, Lipson R, Wolf A, Laufer Y. Effects of dualchannel functional electrical stimulation on gait performance in patients with hemiparesis. Scientific World Journal. 2012;2012:530906.

20. Springer S, Vatine JJ, Wolf A, Laufer Y. The effects of dual-channel functional electrical stimulation on stance phase sagittal kinematics in patients with hemiparesis. J Electromyogr Kinesiol. In press.

21. Folstein MF, Folstein SE, McHugh PR. "Mini-mental state". A practical method for grading the cognitive state of patients for the clinician. J Psychiatr Res. 1975;12(3):189-198.

22. Kosak M, Smith T. Comparison of the 2-, 6-, and 12-minute walk tests in patients with stroke. J Rehabil Res Dev. 2005;42(1):103-107.

23. Flansbjer UB, Holmback AM, Downham D, Patten C, Lexell J. Reliability of gait performance tests in men and women with hemiparesis after stroke. J Rehabil Med. 2005;37(2):75-82.

24. Weinrich M, Good DC, Reding M, et al. Timing, intensity, and duration of rehabilitation for hip fracture and stroke: report of a workshop at the National Center for Medical Rehabilitation Research. Neurorehabil Neural Repair. 2004;18(1):12-28.
25. Bethoux F, Calmels P, Gautheron V. Changes in the quality of life of hemiplegic stroke patients with time: a preliminary report. Am J Phys Med Rehabil. 1999;78(1):19-23.

26. Perera S, Mody SH, Woodman RC, Studenski SA. Meaningful change and responsiveness in common physical performance measures in older adults. J Am Geriatr Soc. 2006;54(5):743-749.

27. Palombaro KM, Craik RL, Mangione KK, Tomlinson JD. Determining meaningful changes in gait speed after hip fracture. Phys Ther. 2006;86(6):809-816.

28. Laufer Y, Ring H, Sprecher E, Hausdorff JM. Gait in individuals with chronic hemiparesis: one-year follow-up of the effects of a neuroprosthesis that ameliorates foot drop. J Neurol Phys Ther. 2009;33(2): 104-110.

29. Burridge JH, Taylor PN, Hagan SA, Wood DE, Swain ID. The effects of common peroneal stimulation on the effort and speed of walking: a randomized controlled trial with chronic hemiplegic patients. Clin Rehabil. 1997;11(3):201-210.

30. Granat MH, Maxwell DJ, Ferguson AC, Lees KR, Barbenel JC. Peroneal stimulator; evaluation for the correction of spastic drop foot in hemiplegia. Arch Phys Med Rehabil. 1996;77(1):19-24.

31. Kottink AI, Hermens HJ, Nene AV, Tenniglo MJ, GroothuisOudshoorn CG, Ijzerman MJ. Therapeutic effect of an implantable peroneal nerve stimulator in subjects with chronic stroke and footdrop: a randomized controlled trial. Phys Ther. 2008;88(4):437-448.

32. Taylor P, Burridge J, Dunkerley A, et al. Clinical audit of 5 years provision of the Odstock dropped foot stimulator. Artif Organs. 1999;23(5):440-442.

33. Hausdorff JM, Ring H. Effects of a new radio frequency-controlled neuroprosthesis on gait symmetry and rhythmicity in patients with chronic hemiparesis. Am J Phys Med Rehabil. 2008;87(1):4-13.

34. Chen G, Patten C, Kothari DH, Zajac FE. Gait differences between individuals with post-stroke hemiparesis and non-disabled controls at matched speeds. Gait Posture. 2005;22(1):51-56.
Clinical Interventions in Aging

\section{Publish your work in this journal}

Clinical Interventions in Aging is an international, peer-reviewed journal focusing on evidence-based reports on the value or lack thereof of treatments intended to prevent or delay the onset of maladaptive correlates of aging in human beings. This journal is indexed on PubMed Central, MedLine, the American Chemical Society's 'Chemical Abstracts Ser-

\section{Dovepress}

vice' (CAS), Scopus and the Elsevier Bibliographic databases. The manuscript management system is completely online and includes a very quick and fair peer-review system, which is all easy to use. Visit http://www.dovepress.com/testimonials.php to read real quotes from published authors. 